\title{
La Colección Hispanoamericana "Dr. J. H. Nunemaker", del State College of Washington
}

\begin{abstract}
A entrar en la sala de la "Colección Hispanoamericana" del State
College of Washington, tenemos una impresión grata, como de bienvenida. La sala está bien iluminada por grandes lámparas cuadrangulares de resplandores azulinos. Estantes con libros ricamente encuadernados cubren las cuatro altísimas paredes hasta el techo. Predominan las encuadernaciones de pasta española, con nítidos caracteres dorados en los lomos.

Hay en la sala dos escritorios: uno, de estilo arcaico, traído de México, todo labrado, sobre el cual se apilan gruesos volúmenes sostenidos por las efigies de madera de dos monjes arrodillados que rezan, leyendo, bajo sus capuchas. El otro escritorio es moderno. Sobre él hay una lámpara de pantalla amarillenta; un rimero, bien ordenado, de libros y catálogos y un par de armarios de metal que contienen fichas. Sentado a este escritorio, lente en mano, un hombre moreno, delgado, de unos cincuenta años, de mediana estatura, impecablemente vestido, diariamente compulsa manuscritos mexicanos coloniales. Un estudiante lee en voz alta la transcripción, recientemente hecha, de un manuscrito. El hombre moreno comprueba, leyendo con la lente en el original, la exactitud de la copia.

Hace semanas, meses, años, que ese hombre moreno realiza en esta sala su labor paciente, disciplinada, exacta. Desde 1929 dirige, en el State College of Washington, el Departamento de Lenguas Extranjeras. Ha hecho varios viajes a España, en su mocedad y en su madurez; ha estudiado en diversas universidades, ha investigado en muchas bibliotecas. En 1921 llegó por primera vez a Madrid. Allí
\end{abstract}


aprendió el español gramaticalmente, en el Centro de Estudios Históricos; lo aprendió de modo tan cabal, que, aprehendiendo el espíritu de la lengua, se adueñó del espíritu de la raza. $\mathrm{El}$ doctor $\mathrm{Nu}-$ nemaker pasa ahora por un español culto, no sólo por la fluencia castiza de su dicción coloreada y fácil, sino que por su físico todo y sus ademanes. Se ha españolizado el doctor Nunemaker; ha hecho amistades valiosas entre los primeros intelectuales de España: Menéndez Pidal, Navarro Tomás, Dámaso Alonso.

Poco a poco, el universitario norteamericano que había llegado a Madrid balbuceando un castellano sacado de los textos, se ha ido identificando con el medio madrileño en que vive. Concurre a la tertulia del café de moda, conversa sobre temas de vida literaria de actualidad; está al tanto de todas las novedades histórico-lingüísticas. En suma : ya pocos tertulianos, al hablar con él, recuerdan que es extranjero.

Desde 1921 la vida y los pensamientos de J. Horace Nunemaker giran en torno a España. Apenas finaliza una estada veraniega en España, Nunemaker traza proyectos entusiastas para un nuevo viaje a Madrid, el verano siguiente. Para ello organiza "tours" de estudiantes angloamericanos deseosos de viajar por la Península. Escribe Nunemaker millares de cartas, lleva a cabo innumerables trámites y el siguiente verano se embarca para España, otra vez, conduciendo un grupo de estudiantes. Estos viajes acrecientan su afán de saber, estimulan su bibliofilia, multiplican su curiosidad intelectual.

El estallido de la guerra civil española interrumpe esta serie de viajes. La guerra mundial hace imposible el acceso al viejo continente, para un soldado de la cultura. Nunemaker, entonces, de la vieja España vuelve los ojos a la Nueva España. Historiador de vocación, Nunemaker experimenta la fascinación del México colonial. Es entonces cuando surge en la mente del estudioso norteamericano la idea de fundar un seminario de estudios hispanoamericanos, especializado en México.

El bibliófilo parte para la ciudad de Moctezuma en busca de libros, documentos y manuscritos. Regresa de México con las primeras aportaciones para el seminario, con catálogos de librerías de viejo y con múltiples proyectos. En el State College of Washington, Nunemaker funda la colección hispanoamericana. Sus labores docentes le absorben todo el día. El bibliófilo, tras una labor incesante, 
lleva al lecho un montón de catálogos de libros y toma copiosas notas, antes de entregarse al sueño. En las primeras horas de la mañana siguiente, hará nuevos pedidos: escribirá a México, Buenos Aires, Santiago, Caracas, Lima, Bogotá, San Francisco, Chicago, Nueva York, Madrid, París. Poco a poco las colecciones de libros más valiosos, más raros, llegan en pesados paquetes, con sellos postales de diferentes países.

A veces, de una obra de diez o doce tomos, Nunemaker ha podido conseguir siete $\mathfrak{u}$ ocho. Nunemaker comenzará una pesquisa larga y paciente por correspondencia y obtendrá, después de meses y meses, de una ciudad distante, un tomo; de otra, o varias otras, los que faltan. Así, durante años.

En 1941 y 1943, viajando por México, Nunemaker se ha relacionado con los coleccionistas de rarezas bibliográficas y se ha entusiasmado con la historia de la inquisición en Nueva España y con la tradición de la familia de los Condes de Regla. De esta familia consiguió valiosos documentos que datan del año de 1549 y constan de 22,000 folios.

Hecha la compra de los manuscritos, el bibliófilo de Pullman debe conseguir permiso del gobierno mexicano, para poder traérselos al seminario hispanoamericano. Los trámites son largos: duran dos, tres, cuatro meses y, al cabo de una espera angustiosa que se prolongó un año, el gobierno de México ha concedido el permiso. Apenas llegan a Pullman los manuscritos, Nunemaker los clasifica, los ordena cronológicamente. Reúne un grupo de estudiantes graduados a los que enseña el método de ordenar documentos, comprender las abreviaturas, descifrar las firmas y, en fin, los inicia pacientemente en los secretos de la paleografía, arte en que él se hizo perito en Madrid, en el Centro de Estudios Históricos, estudiando los lapidarios de Alfonso el Sabio.

En su carácter de conservador de la Colección Hispanoamericana y de Jefe del Departamento de Lenguas Extranjeras del State College of Washington, Nunemaker establece un sistema de tesis para los candidatos al grado de maestro, que consiste en la transcripción de dichos manuscritos, acompañada de un riguroso estudio histórico-lingüístico. En 1949 se nombra a Nunemaker Director de la División de Humanidades. Sus quehaceres se multiplican en intrincada red de problemas administrativos; pero el profesor, el bi- 
bliófilo multiplica también su capacidad de trabajo. Ya no es solamente el scholar devorador de libros, el ensayista que escribe sobre Alfonso el Sabio y M. J. de Larra; el lingüista y dilucidador de acertijos idiomáticos. Nunemaker es, además, el hombre de acción ágil, єjecutivo, fecundo en acertados arbitrios para resolver problemas prácticos de índole diversa. Y, además, como conservador de la Colección Hispanoamericana, Nunemaker sigue siendo el infatigable, escrupuloso director de trabajos paleográficos. Después del almuerzo sobrio, frugal, en cuyo transcurso ha analizado y resuelto, con otros comensales, alguna dificultad administrativa de carácter urgente, $\mathrm{Nu}$ nemaker se apresura para llegar a la sala del seminario.

Al entrar saluda cordialmente a dos o tres estudiantes que le aguardan, echa una cariñosa mirada sobre los estantes de apretados libros; luego se dirige a su escritorio, abre algunas cartas recién llegadas de México o de España; escribe algunas notas en los sobres. En seguida, coge la lente, llama al estudiante que debe leerle la transcripción del manuscrito en estudio, y comienza el cotejo, la paciente labor de benedictino...

Así ha trabajado este erudito de ejemplar sencillez, de fina cortesía, de admirable sentido del humor, durante años y años, en el State College of Washington. Siete son los textos que ha publicado desde 1930 a 1942, y cada uno de esos textos ha significado una rigurosa investigación histórica y literaria. Sus notas al "Macías" de Larra, para dar un ejemplo, representan innumerables lecturas, el planteamiento y la solución de difíciles problemas. Más de cincuenta son los títulos de artículos y ensayos debidos a su pluma. Nunemaker ha sido siempre un cazador de temas curiosos: aspectos de la alquimia o la obstetricia medievales; la revelación de olvidadas costumbres coloniales mexicanas que surge de un polvoriento manuscrito; algún rasgo original de nigromancia o astrología del tiempo de Alfonso el Sabio...

E1 24 de junio anterior, inesperadamente, fallece en Spokane el doctor J. Horace Nunemaker. Su obra no está terminada. El, sin embargo, ha dejado un plan, una dirección y un verdadero tesoro de libros y documentos que son legítimo orgullo del State College of Washington. 
No hace mucho, un profesor de California, especialista en cultura hispanoamericana, visitó la colección, examinó los ficheros, escudriñó en los anaqueles. Al salir de la sala dijo: "Cuando algún estudioso mexicano quiera esclarecer aspectos nunca tratados de la historia de su país, tendrá que venir a Pullman y trabajar en esta colección."

Por sugestión del presidente del State College of Washington, doctor Wilson Compton, el Consejo de Regentes de esa institución ha resuelto dar a la Colección Hispanoamericana de Pullman el nombre de su fundador, doctor J. Horace Nunemaker.

\author{
Hugo Rodríguez Alcalá, \\ State College of Washington, \\ Pullman, Wash.
}


